\title{
The CFD Modeling of Multiphase Flow in an SKS Furnace: The Effect of Tuyere Diameter and Bath Depth
}

\author{
KEZHOU SONG ${ }^{1}$ and ARI JOKILAAKSO (i] ${ }^{1,2}$ \\ 1.-School of Chemical Engineering, Department of Chemical and Metallurgical \\ Engineering, Aalto University, P.O. Box 16100, FI-00076 Aalto, Finland. \\ 2.—e-mail: ari.jokilaakso@aalto.fi
}

CFD simulation using a multi-fluid VOF model on scaled-down SKS furnace multiphase flow was conducted, targeting the agitation performance under conditions of different tuyere diameters and bath depths, at a constant total gas volumetric flow rate. The results indicate that an increased bath depth contributes to the lateral movements of the matte and air phased, significantly promoting the agitation at the far side of the plumes. The characteristic of a deep bath allows larger tuyere diameters operated at a lower gas injection speed, to achieve comparatively smaller low velocity regions and dead zones. In addition, the wall shear stress was found to correlate with the distribution of low-velocity regions. Since the selections of tuyere diameter and bath depth are of major importance in the optimizing of flow fields, the results from this simulation offer good references for the future operation and design of SKS furnaces and other similar industrial vessels.

\section{INTRODUCTION}

The production capacity of refined copper has been increasing for the last 60 years, due to growing market demand worldwide. ${ }^{1}$ To improve the production efficiency and environmental protection performance, copper smelting and converting technologies have been continuously optimized. ${ }^{1,2}$ Apart from flash smelting technology, which is expected to account for $67 \%$ of world total copper smelting capacity in 2024, the rapid expansion of Chinese technology has also been noted and is predicted to increase from nearly $0 \%$ to $14 \%$ in the period of 2000-2024. ${ }^{1}$ The growing scale of this emerging technology accords with that of the reported SKS (ShuiKouShan) technology or bottom-blown coppersmelting technology, which has gradually become popularized in East Asia in the last 15 years. ${ }^{3,4}$ The SKS furnace has good operating efficiency and environmental performance, thus attracting growing interest. ${ }^{3,4}$ Furthermore, as a bath-smelting technology, which significantly lowers the raw material grinding cost, SKS technology shows great

(Received October 17, 2021; accepted December 26, 2021; published online January 25, 2022) potential for secondary resource recovery. Such advantages will contribute to the treatment of raw materials of comparatively large size, especially electronic waste including WPCB (waste printed circuit boards), the amount of which has grown rapidly. ${ }^{5,6}$

Based on the current situation, SKS technology will be a promising way to meet the increasing demand for higher production efficiency, less pollution discharge, and better raw material adaptation. However, as a new technology, ${ }^{7,8}$ its furnace design and detailed parameters have yet to not be fully optimized. This is partly due to the fact that SKS furnace designs differ from company to company, thus the sizes and parameters tested by different research groups also vary a lot. This has meant that some of the reported work regarding SKS furnaces can only be used in very limited conditions. Reported investigations on the SKS furnace flow field have been implemented mainly using two approaches, i.e., water model experiments and CFD (computational fluid dynamics) simulations. Water model research usually targets the mixing time and standing waves. ${ }^{9-11}$ Combined with particle image velocimetry technology, the velocity distribution at a certain cross-section can be revealed. ${ }^{12}$ Due to the large scale and complexity 
of the SKS furnace, which causes great processing difficulties for the water model equipment, mostly only one nozzle is used, without tests for a complete scaled-down SKS furnace model. Such simplification leads to ignorance of the interactions between adjacent nozzles. Additionally, water model experiments are carried out based on the Law of Similarity, which inevitably differs from the real matte flow. Hence, for some of the flow field investigations, such as the observation of the velocity distribution and wall shear stress for the whole furnace model, water model experiments are usually not able to supply comprehensive results, and, instead, CFD simulation research is necessary. For the simulation of multiphase flow in SKS furnaces, typically the VOF (volume of fraction) model and Eulerian model are adopted. The VOF model, capable of tracking the interface of a multiphase flow, has been applied in SKS furnace simulation, as reported by Yan et al. ${ }^{13}$ and Dong et al. ${ }^{14}$ with the construction of 2D (2-dimension) and 3D (3-dimension) physical models, respectively. In both research studies, the bubble or plume shape was verified by comparison with captured real water model images. However, simply comparing the shape of the bubbles cannot ensure that the simulated flow field accurately represents reality. In 2019, a CFD work on an SKS furnace using the Eulerian model was reported by Shao et al., ${ }^{15}$ with mixing efficiency investigations carried out and verified by the mixing time. The research from Shao et al. provided informative results, but it cannot be directly used as a reference because they did not state the tuyere diameter, which has a significant effect on the flow field by determining the gas injection speed.

The reported water model experimental research and CFD simulation research on SKS furnaces are listed in Table I. As can be seen, the research on SKS furnace flow phenomena was implemented based on different physical models and model verification approaches. To systematically explore the flow field of an SKS furnace, a more reliable model verification method was proposed in our previous research in $2021 .{ }^{16}$ In the previous work, the multi-fluid VOF model was first used in SKS furnace simulation, with verification not only of the plume shape but also of the wave frequency and wave amplitude. ${ }^{16}$ To ensure that the simulation results could be helpful to most SKS cases, the parameters were selected from the common range used in industry. In particular, the tuyere diameter, which is a very important parameter although sometimes ignored, was selected to be $60 \mathrm{~mm}$, from the common range of $48-72 \mathrm{~mm} \cdot{ }^{17}$ In the current work, the previous numerical model and basic furnace sizes are used, with analysis of flow fields at different tuyere diameters and bath depths. The related results in the current simulation contribute to a better understanding of the flow field in an SKS furnace, and, furthermore, offering good references for future furnace operation and design.

Table I. Reported research on the flow phenomena of SKS furnaces

\begin{tabular}{|c|c|c|c|c|c|c|c|}
\hline $\begin{array}{l}\text { Research } \\
\text { group }\end{array}$ & Model & $\begin{array}{l}\text { Model } \\
\text { scale }\end{array}$ & $\begin{array}{c}\text { Model } \\
\text { verification }\end{array}$ & $\begin{array}{l}\text { Liquid } \\
\text { phase }\end{array}$ & $\begin{array}{l}\text { Tuyere } \\
\text { diameter }\end{array}$ & Research output & Ref. \\
\hline $\begin{array}{l}\text { Wang et al. } \\
2017\end{array}$ & $\begin{array}{l}\text { Water } \\
\text { model }\end{array}$ & $\begin{array}{l}\text { Single } \\
\text { nozzle }\end{array}$ & / & Water & $15 \mathrm{~mm}$ & $\begin{array}{l}\text { A cross-section velocity dis- } \\
\text { tribution }\end{array}$ & 12 \\
\hline $\begin{array}{l}\text { Shui et al. } \\
2015-2018\end{array}$ & $\begin{array}{l}\text { Water } \\
\text { model }\end{array}$ & $\begin{array}{l}\text { Single } \\
\text { nozzle }\end{array}$ & / & $\begin{array}{c}\text { Water/ } \\
\text { oil-wa- } \\
\text { ter }\end{array}$ & $60 \mathrm{~mm}$ & $\begin{array}{c}\text { Mixing time and of standing } \\
\text { waves }\end{array}$ & $\begin{array}{l}9- \\
11\end{array}$ \\
\hline $\begin{array}{l}\text { Yan et al. } \\
2012\end{array}$ & CFD-VOF & $\begin{array}{c}\text { Single } \\
\text { tuyere } \\
\text { (2D) }\end{array}$ & Bubble shape & Matte & $60 \mathrm{~mm}$ & $\begin{array}{l}\text { Optimization of tuyere angle } \\
\text { and diameter }\end{array}$ & 13 \\
\hline $\begin{array}{l}\text { Dong et al. } \\
2019\end{array}$ & CFD-VOF & $\begin{array}{l}\text { Full- } \\
\text { scale } \\
(3 D)\end{array}$ & Plume shape & $\begin{array}{l}\text { Slag- } \\
\text { matte }\end{array}$ & Unreported & $\begin{array}{l}\text { General analysis of flow } \\
\text { field and splashing }\end{array}$ & 14 \\
\hline
\end{tabular}




\section{MATHEMATICAL MODEL}

The performance of the multi-fluid VOF model adopted in this simulation was verified in our previous CFD study. ${ }^{16}$ The description of the math is as follows.

\section{Governing Equations}

The mass and momentum conservation equations for phase $q$ (including the gas phase and liquid phase) are given as Eqs 1 and $2,{ }^{16}$ respectively:

$$
\begin{gathered}
\frac{\partial}{\partial t}\left(\alpha_{q} \rho_{q}\right)+\nabla\left(\alpha_{q} \rho_{q} \vec{v}_{q}\right)=0 \\
\frac{\partial}{\partial t}\left(\alpha_{q} \rho_{q} \vec{v}_{q}\right)+\nabla\left(\alpha_{q} \rho_{q} \vec{v}_{q} \vec{v}_{q}\right) \\
=-\nabla p+\nabla\left[\mu\left(\nabla \vec{v}_{q}+\nabla \vec{v}_{q}^{T}\right)\right]+\alpha_{q} \rho_{q} \vec{g}+\vec{f} \\
\alpha_{q}=\alpha_{g} \text { or } \alpha_{l}, \alpha_{g}+\alpha_{l}=1
\end{gathered}
$$

In Eqs. (1)-(3), $\alpha$ is the volume fraction, $\rho$ is the density, $\vec{v}$ is the velocity, $p$ is the pressure shared by both two phases, $\alpha_{q} \rho_{q} \vec{g}$ is the gravity term, and $\vec{f}$ is an external body force which is specifically defined as the drag force in the current system. The subscripts $g$ and $l$ represent the gas and liquid phases, respectively.

\section{Drag Force}

In the current simulation, due to a very high injection speed, the drag force is preferentially considered, ignoring other interphase forces, such as the turbulence dispersion force, which usually influence the flow field at a much lower speed range. Since detailed bubble behavior is not discussed in this work, the simplification does not affect the result analysis and helps to improve the calculation efficiency. Drag force is introduced based on the symmetric model provided by the multi-fluid VOF model. ${ }^{19}$ For the symmetric model, density and viscosity are calculated from volume averaged properties:

$$
\begin{aligned}
& \rho_{g l}=\alpha_{g} \rho_{g}+\alpha_{l} \rho_{l} \\
& \mu_{g l}=\alpha_{g} \mu_{g}+\alpha_{l} \mu_{l}
\end{aligned}
$$

and the diameter of bubbles or droplets is defined as:

$$
d_{g l}=\frac{1}{2}\left(d_{g}+d_{l}\right)
$$

In turn, the drag function is given as:

$$
f=\frac{C_{D} R e}{24}
$$

where the relative Reynold number $R e$ is:

$$
R e=\frac{\rho_{g l}\left|\vec{v}_{g}-\vec{v}_{l}\right| d_{g l}}{\mu_{g l}}
$$

and the drag coefficient $C_{D}$ is:

$$
C_{D}=\left\{\begin{array}{c}
24\left(1+0.15 R e^{0.687}\right) / R e R e \leq 1000 \\
0.44 R e \geq 1000
\end{array}\right.
$$

The drag force is only affected by the bubble or droplet diameter, since the values of the other variables are all taken from industrial data. In the SKS furnace, the gas injection speed for the quasijetting flow regime is very high, compared to the common situation in other copper-making processes with bubbly flow regimes. ${ }^{20-23}$ The bubbles aggregate into a bubble group or larger bubbles of irregular shape, based on the experimental photographs from Shui et al. ${ }^{10}$ Therefore, as the bubbles tend to aggregate and probably coalesce, consideration is given primarily to the continuity of the bubble plume. As proposed earlier, ${ }^{16}$ the bubble plume is regarded as a bubble ribbon. This enables the gas phase to be set as a continuous phase and hence the droplet diameter is defined instead. The diameter value was determined based on whether the plume shape (or ribbon shape) agreed with the experimental images ${ }^{10}$ and finally the default value of $0.00001 \mathrm{~m}$ was adopted.

\section{Turbulence Models}

The standard $k-\varepsilon$ turbulence model with standard wall functions is adopted for the present simulation. The kinetic energy $k$ and its rate of dissipation $\varepsilon$ yields are:

$$
\begin{aligned}
\frac{\partial}{\partial t}\left(\rho_{m} k\right)+\nabla\left(\rho_{m} \vec{v}_{m} k\right)= & \nabla\left(\alpha_{l} \frac{\mu_{t}}{\sigma_{k}} \nabla k\right)+G_{k}+G_{b} \\
& -\rho_{m} \varepsilon \\
\frac{\partial}{\partial t}\left(\rho_{m} \varepsilon\right)+\nabla\left(\rho_{m} \vec{v}_{m} \varepsilon\right)= & \nabla\left(\frac{\mu_{t}}{\sigma_{k}} \nabla \varepsilon\right) \\
& +\frac{\varepsilon}{k}\left(C_{1 \varepsilon}\left(G_{k}+G_{b}\right)\right)-C_{2 \varepsilon} \rho_{m} \varepsilon
\end{aligned}
$$

where $G_{k}$ represents the generation of turbulence energy due to the mean velocity gradients, and $G_{b}$ is the turbulence energy due to buoyancy. The mixture density $\rho_{m}$ and mixture velocity $\vec{v}_{m}$ are defined as:

$$
\rho_{m}=\alpha_{g} \rho_{g}+\alpha_{l} \rho_{l}
$$

$$
\vec{v}_{m}=\frac{\alpha_{g} \rho_{g} \vec{v}_{g}+\alpha_{l} \rho_{l} \vec{v}_{l}}{\alpha_{g} \rho_{g}+\alpha_{l} \rho_{l}}
$$


The empirical constants are $C_{1 \varepsilon}=1.44$, $C_{2 \varepsilon}=1.92, \sigma_{k}=1, \sigma_{k}=1.3$. The turbulence viscosity $\mu_{t}$ is given as Eq. (14).

$$
\mu_{t}=\rho_{m} C_{\mu} \frac{k^{2}}{\varepsilon}, C_{\mu}=0.09
$$

\section{GEOMETRY AND SIMULATION CONDITIONS}

\section{Physical Model}

In this work, simulated scaled-down SKS furnace models were created for a prototype at a ratio of 1:12. The related parameters are shown in Table II. According to our previous research, ${ }^{16}$ the $0^{\circ}+14^{\circ}$ tuyere arrangement has been proved to have a better agitation performance and less side wall impact compared with the original $7^{\circ}+22^{\circ}$ Fangyuan arrangement; the tuyere arrangements on either side of the furnace may require an extra readjustment of the furnace structure and furnacesupporting facilities. Also, disadvantages have been reported for the $7^{\circ}+22^{\circ}$ tuyere angle combinations, based on experiences from our previous CFD study. ${ }^{16}$ Therefore, the $0^{\circ}+14^{\circ}$ tuyere arrangement is regarded as a most promising tuyere arrangement and has been adopted in this work, as shown in Fig. 1. The tuyere diameter and bath depth are set as the variables. For all the presented cases, the total volumetric gas flow rate is fixed, correspondingly converted from the comparatively high value of $12,000 \mathrm{~m}^{3} \mathrm{~h}^{-1}$. This is in the range of the commonly used $5000-15,000 \mathrm{~m}^{3} \mathrm{~h}^{-1}$, as the gas volumetric gas flow rate tends to be improved to achieve higher production efficiency in industry. With a constant total volumetric gas flow rate, the gas injection speed is determined by the simulated tuyere diameter. The volumetric gas flow rate was calculated based on the modified Froude number, $F r$, which is given as Eq. (15):

$$
F r_{m}^{\prime}=\frac{\rho_{g m} u_{m}^{2}}{\left(\rho_{l m}-\rho_{g}\right) g L_{m}}=\frac{\rho_{g p} u_{p}^{2}}{\left(\rho_{\mathrm{lg}}-\rho_{g p}\right) g L_{p}}=F r_{p}^{\prime}
$$

where subscript $m$ represents the simulated SKS furnace model, subscript $p$ represents the prototype, $u$ is the volumetric gas flow rate, and $L$ is the characteristic length.

To improve the calculation efficiency, the following simplifications have been implemented in the physical model:

1. The furnace structure is simplified as a simple cylinder.

2. There is no heat and mass transfer in the physical model. This would not have a major influence on the simulation accuracy as the key parameters of high-temperature matte and oxygen enrichment remain.

3. There is no slag phase present in the water model as a small amount of slag is not able to significantly affect the bubble plume. Also, the results in the current work should be regarded as a simulation of the initial operating stage in an SKS furnace. The agitation performance with a thick slag layer will be conducted as an independent research study in the future.

\section{CFD Modeling}

\section{CFD Setup}

The mesh of the simulated SKS furnace is shown in Fig. 2, from which it can be seen that the hexahedral mesh was constructed with multizone meshing for each case. Using the same mesh treatment as that of our previous work, the gas inlets of very small size (less than $1 / 48$ of the furnace section diameter) were simplified and made square to improve the mesh quality and calculation efficiency. The simplification has been verified by a preliminary mesh test to make sure that the macroscopic velocity distribution and wall shear stress would not

\begin{tabular}{|c|c|c|}
\hline & Prototype $^{12,17}$ & Simulated scaled-down SKS furnace \\
\hline Inner diameter $[\mathrm{mm}]$ & 3490 & 290 \\
\hline Length $[\mathrm{mm}]$ & 15,084 & 1250 \\
\hline Number of operational tuyeres & 9 & 9 \\
\hline Tuyere diameter $[\mathrm{mm}]$ & 60 & $4-6$ \\
\hline Tuyere angle & $7^{\circ}+22^{\circ}$ & $0^{\circ}+14^{\circ}$ \\
\hline Depth of liquid $[\mathrm{mm}]$ & $1200-1800$ & 100,145 \\
\hline Gas volumetric flow rate $\left[\mathrm{m}^{3} \mathrm{~h}^{-1}\right]$ & $5000-15,000$ (in total) & 24 (in total) \\
\hline Gas/gas density $\left[\mathrm{kg} \mathrm{m}^{-3}\right]$ & Enriched oxygen/1.38 & Air/1.38 \\
\hline Matte density $\left[\mathrm{kg} \mathrm{m}^{-3}\right]$ & 4440 & 4440 \\
\hline Matte viscosity [Pa s] & 0.004 & 0.004 \\
\hline Matte interface tension $\left[\mathrm{N} \mathrm{m}^{-3}\right]$ & 0.33 & 0.33 \\
\hline
\end{tabular}

Table II. Parameters of the prototype, water model, simulated water model, and simulated SKS furnace 


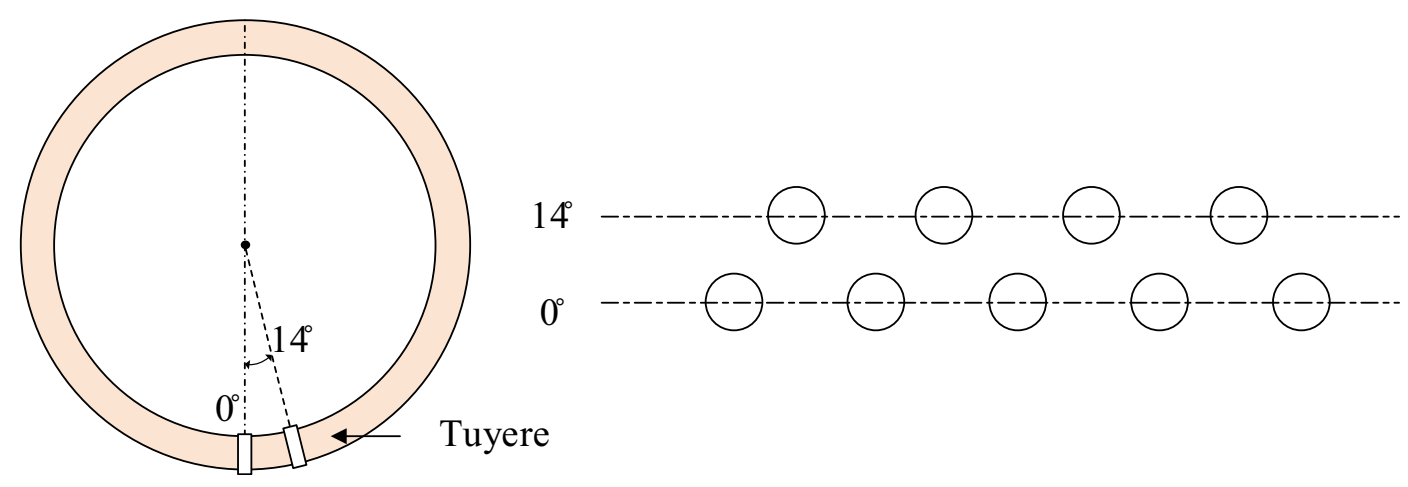

Fig. 1. Schematic of the tuyere angle and tuyere arrangements for this simulation.

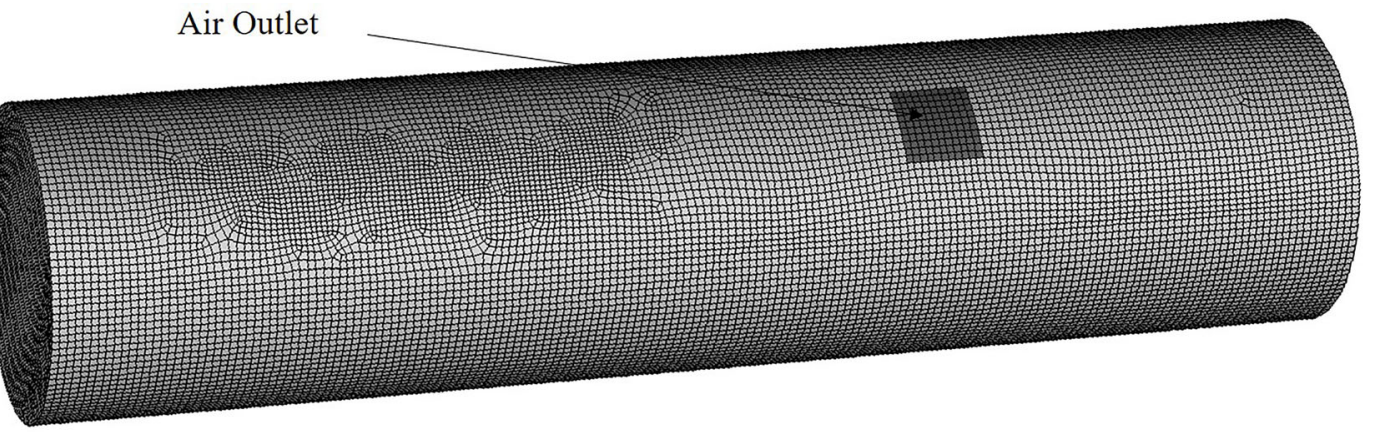

(b) Air Inlet

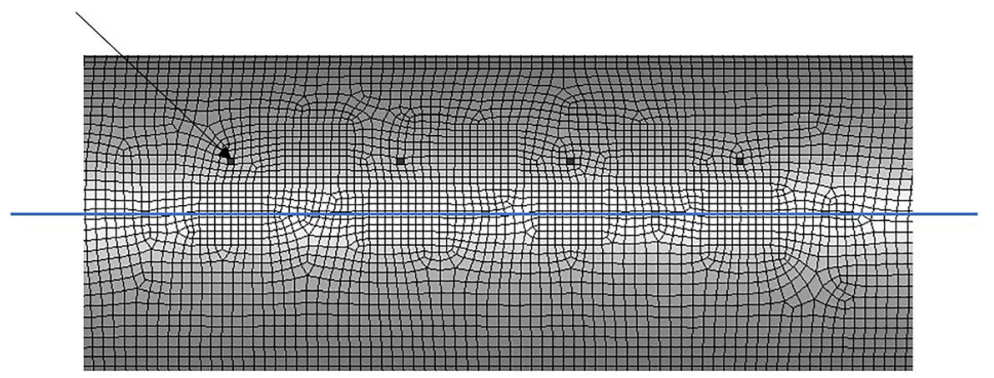

(c) Mesh of the agitation zone cross-section at blue line

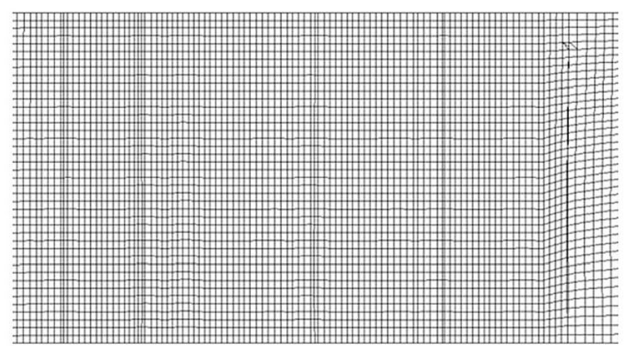

Fig. 2. (a) Mesh of the simulated SKS furnace. (b) Mesh arrangement of the tuyere area. Cells in full black are the inlets where tuyeres are located. (c) Mesh of the agitation zone cross-section marked with a blue line from (b).

be influenced by the inlet mesh treatment and mesh size. ${ }^{16}$ The number of cells with the current meshing setup was eventually set within the range of 310,000-330,000. For each mesh of cases with different tuyere diameters, more than $99.877 \%$ of the elements are of a skewness below 0.50, which translates into good or excellent cell quality. The others, less than $0.123 \%$, are of a skewness below 0.61 , evaluated as fair cell quality. ${ }^{24}$

As shown in Fig. 2, the gas inlets are located at the furnace bottom and set as the velocity inlet. The gas outlet is located at the top surface at a distance from the agitation zone and was set as the pressure outlet. The time-step was set as $5 \times 10^{-4} \mathrm{~s}$, and the convergence marked by a dimensionless residual of less than $1 \times 10^{-3}$. All of the control equations in this simulation were calculated using the commercial software Ansys Fluent 2019 R3.

\section{Verification of the Numerical Model}

In our previous study, the numerical model has been proved to be capable of geometrically reconstructing the bubble plumes in terms of plume position and plume shape. Furthermore, the wave characteristics were found to agree well with the experimental water model tests reported by Shui et al. ${ }^{10}$. The dimensionless wave frequency of the simulated water model was found to be 1.495 , which is very close to the reported 1.566 of the corresponding water model experiment. ${ }^{10}$ More specifically, an asymmetric standing wave was observed to appear 29 times in the simulated $20 \mathrm{~s}$, and was reported to appear 30 times in the real water model test during the same time length. The wave amplitude was also in the reported range derived from the water model test results gained in very similar conditions. ${ }^{16}$ As the standing waves could only be generated at a 
certain gas injection speed and bath depth, the almost identical wave performance indicated that, under the same or similar conditions, an extremely similar flow field could be constructed using the current numerical model. The related detailed verification processes and figures can be seen in our previous work. $^{16}$

\section{RESULTS AND DISCUSSION}

In this study, the effect of the tuyere diameter and bath depth on the SKS flow field is presented and analyzed. Considering that the equilibrium in the furnace should be kept steady and would be broken by a significantly changed gas volumetric flow rate, the total gas volumetric flow rate was set as constant, and the gas injection speed was changed with the tested tuyere diameters. To investigate the flow fields comprehensively with different tuyere diameters, the bath depth was also adjusted as a variable. By comparing the simulation results under different conditions, basic rules for the macroscopic flow fields could be found.

The simulation results were derived from a certain period within the simulation time range of 0-10 s. A period of sufficient flow motion was included in this time length, as it was observed that the volume of low velocity regions dramatically changed in as little as around $0.5 \mathrm{~s}$. To visualize the results, an agitation zone was selected (shown in Fig. 3) in which the low velocity region was exhibited (see sections 4.1 and 4.2), and the corresponding region volume fraction was also calculated.

In an SKS furnace, high-speed gas fiercely agitates the bath in the agitation zone, resulting in a very asymmetrical velocity distribution. In the zones surrounding a plume which are of higher matte velocity, the physical interaction between matte and air is strong, and the chemical reaction will progress efficiently, because the gas-liquid contact is sufficient. However, for the low-velocity regions located at the far side of the plume, the reaction efficiency could depend on bubble recycling and diffusion. To enhance the gas-liquid contact in the whole bath, it is necessary to reduce the volume of the low-velocity regions. Hence, in this simulation, the distribution of low-velocity regions is regarded as a crucial point in evaluating the general agitation performance. A low-velocity region is defined as the area with a matte velocity of below $0.05 \mathrm{~m} \mathrm{~s}^{-1}$, the value of which is derived from the low-velocity region in the case of a tuyere diameter of $60 \mathrm{~mm}$ (5 mm for the simulated SKS furnace) ${ }^{16}$ which is the average value within the reported range. ${ }^{17}$ The surface tension which would influence the low-velocity region, is from the reported industrial data (shown in Table II), to be close to most of the industrial situations.

\section{Effect of Tuyere Diameters with Increased Bath Depth}

In this section, the effect of tuyere diameters with a bath depth of $145 \mathrm{~mm}$ is analyzed by presenting the distribution of low-velocity regions and wall shear stress.

\section{Distribution of Low-Velocity Regions}

The images of the low-velocity regions were recorded every $0.25 \mathrm{~s}$ during a period of $5-10 \mathrm{~s}$. To show the situation at each of these moments, a total of 21 images for each moment were overlapped with 95\% transparency. These overlapped images are shown in Fig. 4a-c, corresponding to cases in the conditions of a tuyere diameter of $4 \mathrm{~mm}, 5 \mathrm{~mm}$, and $6 \mathrm{~mm}$, respectively. The detailed low-velocity region distribution is illustrated by a gradual color change; the legend bar is shown at the bottom of Fig. 4. In general, according to Fig. $4 \mathrm{a}-\mathrm{c}$, the largest lowvelocity regions are located in the area near the wall. It can be seen that, the closer to the side wall, the smaller the matte velocity tended to be. This could be regarded as a basic velocity distribution characteristic in the current simulation, as it is not associated with the change in tuyere diameter.

The color saturation should be noticed in order to comprehend the relationship between velocity distribution and different tuyere diameters. An area with higher saturation represents the fact that the low velocity region appeared more frequently. As illustrated, the color saturations for Fig. $4 \mathrm{a}$ and b are at a lower level, compared with a significantly increased saturation for Fig. 4c. This suggests that, with the tuyere diameter of $6 \mathrm{~mm}$, the low-velocity regions expanded to a much larger extent, or, in

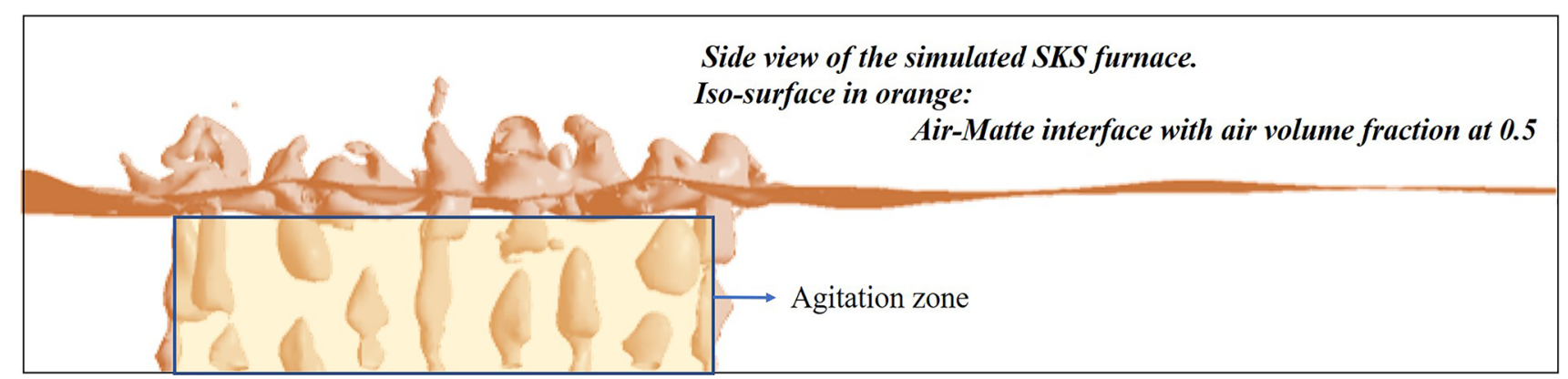

Fig. 3. Investigated agitation zone in this simulation. 

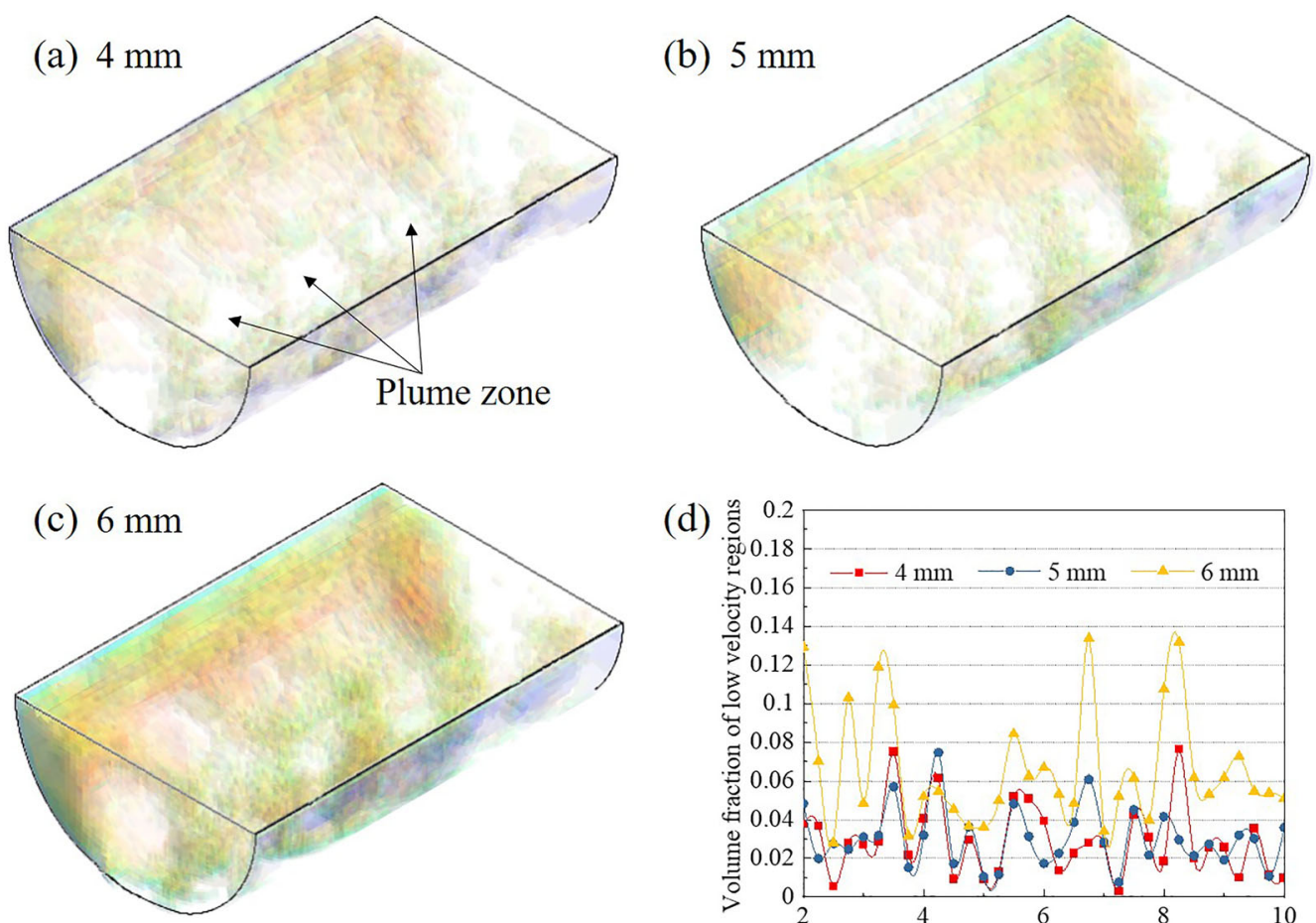

(d)
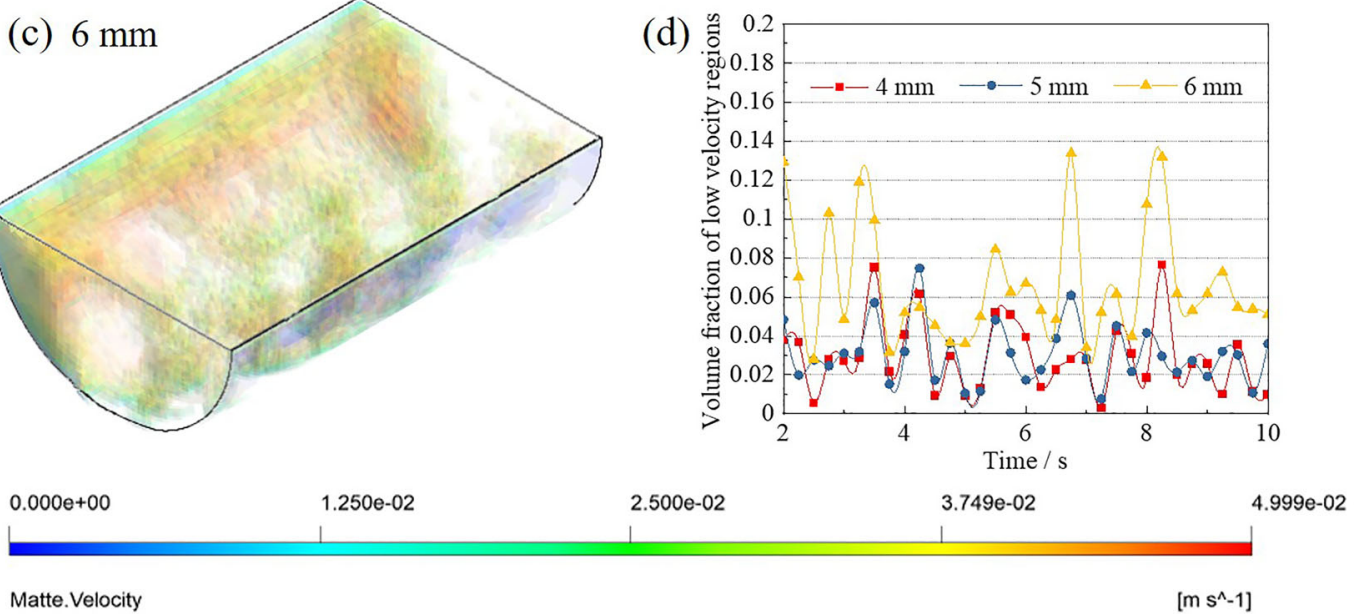

[m s $\left.\mathrm{s}^{\wedge}-1\right]$

Fig. 4. Distribution of low-velocity regions (matte velocity less than $0.05 \mathrm{~m} \mathrm{~s}^{-1}$ ) with different tuyere diameters. (a-c) superpositions of the lowvelocity regions from 5 to $10 \mathrm{~s}$, in conditions of bath depth: $145 \mathrm{~m}$, tuyere diameter: (a) $4 \mathrm{~mm}$, (b) $5 \mathrm{~mm}$, (c) $6 \mathrm{~mm}$, Re: (a) 261,826, (b) 209,235, (c) 174,492 . The legend bar at the bottom shows the velocity estimation for (a-c). (d) Variation in volume fractions of the low-velocity regions from 2 to $10 \mathrm{~s}$, with tuyere diameters of $4 \mathrm{~mm}, 5 \mathrm{~mm}, 6 \mathrm{~mm}$, and bath depth of $145 \mathrm{~mm}$.

other words, the flow field became quieter. The appearance of such a quieter agitation zone was attributed to the fact that, at a constant total gas volumetric flow rate, the gas injection speed had to be slower to compensate the larger tuyere diameter. Besides the case shown in Fig. 4c, the situations in Fig. $4 \mathrm{a}$ and $\mathrm{b}$ also deserve further notice. Basically, the saturations in Fig. $4 \mathrm{a}$ and $\mathrm{b}$ are at the same level, as the low velocity regions for the cases of tuyere diameters of $4 \mathrm{~mm}$ and $5 \mathrm{~mm}$ are both small. This means that, even though the gas injection speed is changed for different tuyere diameters, the distribution of low-velocity regions might not be significantly affected accordingly. To further illustrate the low-velocity flow field, a digitalized variation of the low velocity regions in the conditions of different tuyere diameters is presented in Fig. 4d. As expected, the volume fraction curves in Fig. 4d are in good agreement with the saturation behavior in Fig. $4 \mathrm{a}-\mathrm{c}$. It can be observed that the volume fractions of low-velocity regions for the cases of tuyere diameters of $4 \mathrm{~mm}$ and $5 \mathrm{~mm}$ are similar and both in a low range. For the case of the 6-mm tuyere diameter, the volume fraction of the low velocity regions increases dramatically, which is in good accordance with the higher color saturation in Fig. 4c. Therefore, from the agitation point of view, if the bath depth is usually set at a high level, the tuyere diameter is suggested to be $4 \mathrm{~mm}$ or $5 \mathrm{~mm}$ for simulated scaled-down SKS furnace, and $48 \mathrm{~mm}$ or $60 \mathrm{~mm}$ for industrial furnaces.

\section{Wall Shear Stress}

The distribution of wall shear stress with tuyere diameters of $4 \mathrm{~mm}, 5 \mathrm{~mm}$, and $6 \mathrm{~mm}$ is shown in Fig. 5, in which, based on the images, the areas surrounding the tuyere are in the darkest orange, indicating that the wall shear stress in these areas is at the strongest level, regardless of the tuyere diameter. For the cases with tuyere diameters of 4 $\mathrm{mm}$ and $5 \mathrm{~mm}$ (Fig. 5a and b), the wall shear stress is at the same level, and is much stronger than with the tuyere diameter of $6 \mathrm{~mm}$ (Fig. 5c). Such a performance agrees well with the low velocity distribution discussed in section 4.1.1. The smaller low velocity regions means that the matte was moving at a relatively higher speed, and, therefore, the impact on the furnace wall was stronger, as seen in Fig. 5a and b. With a lower injection speed for the tuyere diameter of $6 \mathrm{~mm}$, shown in Fig. 5c, the flow 
(a)

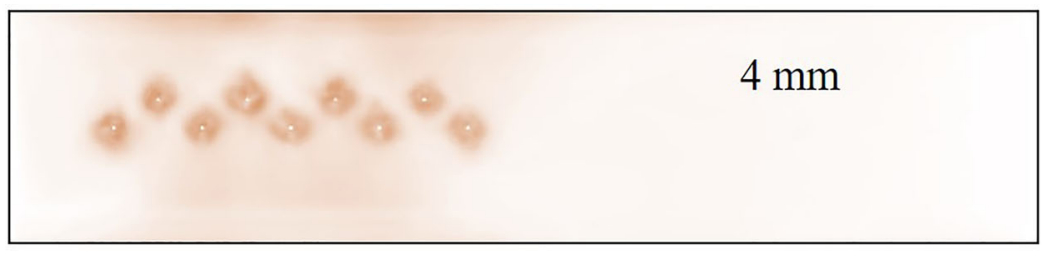

(b)

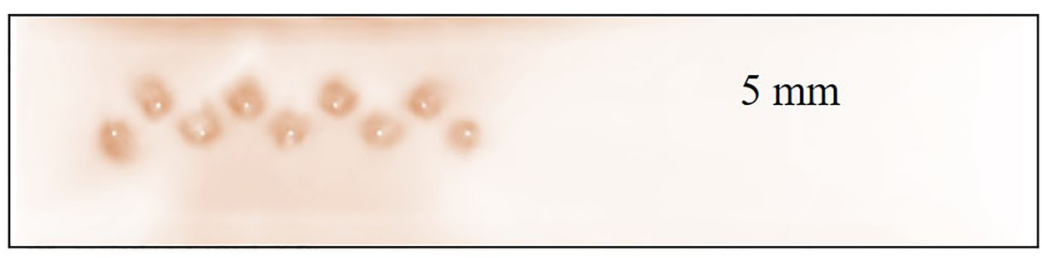

(c)

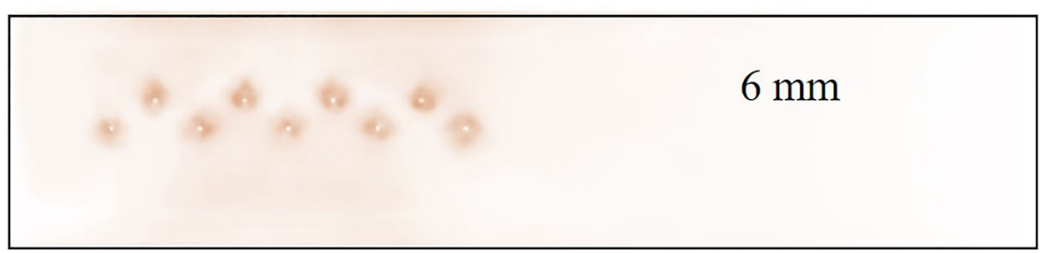

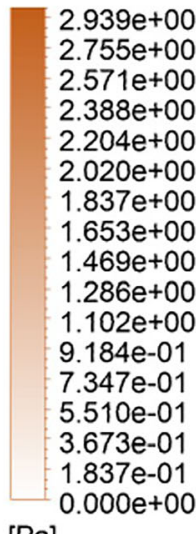

$[\mathrm{Pa}]$

Fig. 5. Bottom view of the superposition of the wall shear stress in 5-10 s. The images were taken each $0.25 \mathrm{~s}$, and each image has been set with $95 \%$ transparency. Conditions: bath depth $145 \mathrm{~m}$, tuyere diameter (a) $4 \mathrm{~mm}$, (b) $5 \mathrm{~mm}$, (c) $6 \mathrm{~mm}$.

fields became quieter, and the wall impact correspondingly decreased. In general, in these conditions, the wall shear stress was found to be strongly associated with the distribution of the low-velocity region. To alleviate the impact on the lining refractory, changing the tuyere diameter might not be an efficient way, as it must be combined with sacrificing furnace agitation efficiency.

\section{Effect of Tuyere Diameters with Shallow Bath Depth}

In this seciotn, the effect of tuyere diameter with a decreased bath depth of $100 \mathrm{~mm}$ is presented using the same approaches as in section 4.1. A direct comparison could be implemented to further explore not only the effect of tuyere diameters, but also the effect of different bath depths on agitation performance.

\section{Distribution of Low-Velocity Regions}

Using the same image treatment as in Fig. 4, the superposition of the low-velocity region images from 5 to $10 \mathrm{~s}$, at a bath depth of $100 \mathrm{~mm}$, and tuyere diameters of $4 \mathrm{~mm}, 5 \mathrm{~mm}$, and $6 \mathrm{~mm}$, is shown in Fig. $6 a-c$, respectively. As can be seen, the lowvelocity regions are widely distributed in the investigated agitation zone, with the majority located in the areas near the walls, which is presented with higher color saturation. With the shallow bath depth, the distribution of low-velocity regions was found to have a strong relationship to a change in tuyere diameter. When the tuyere diameter was increased from 4 to $5 \mathrm{~mm}$, as presented in Fig. $6 \mathrm{a}$ and $b$, the colored low-velocity regions slightly expanded and moved closer to the plume zone. In the case of the tuyere diameter of $6 \mathrm{~mm}$, such expansion was more significant, as it can be noticed that even the plume zone was covered to some extent. The visualized velocity distribution is further confirmed by the digitalized curves presented in Fig. 6d, in whicyh it can be seen that the volume level of the low-velocity regions increased with a larger tuyere diameter, showing good agreement with (a-c). Unlike the increased bath depth of 145 $\mathrm{mm}$ described in section 4.1, the effect of the tuyere diameter on the volume of low-velocity regions is amplified in the case of the shallow bath depth. Such an enhancement could be noticed with the velocity distribution difference between the situations with tuyere diameters of $4 \mathrm{~mm}$ and $5 \mathrm{~mm}$, whereas, in the case of the increased bath depth, there is no significant difference. The reason for the amplified influence could be attributed to the very different gas moving path. When the bath depth was shallow, the simulated gas reached the bath level in a comparatively short time, without sufficient time and space for further diffusion. When the bath depth was deep, the drag force on the gas plume was maintained for a longer time, and, therefore, contributed to the lateral motion of the bubbles and enhanced the flow circulation.

\section{Wall Shear Stress}

The bottom view of the wall shear stress with a shallow bath depth and different tuyere diameters is shown in Fig. 7. Compared with the cases of increased bath depth presented in Fig. 5, the color 

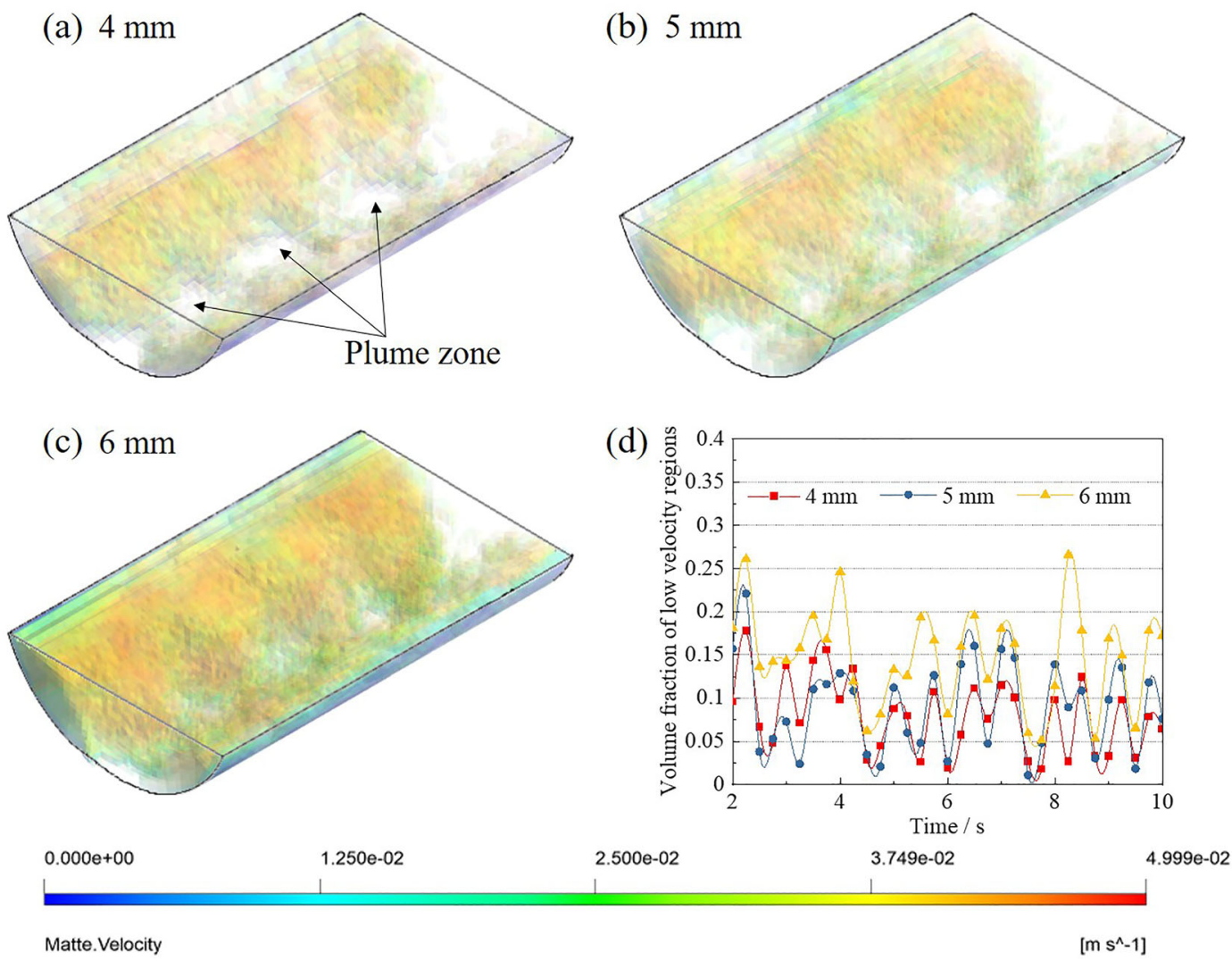

Fig. 6. Distribution of low-velocity regions (matte velocity less than $0.05 \mathrm{~m} \mathrm{~s}^{-1}$ ) with different tuyere diameters. (a-c) Superpositions of the low velocity regions from 5 to $10 \mathrm{~s}$, in conditions of bath depth: $100 \mathrm{~m}$, tuyere diameter: (a) $4 \mathrm{~mm}$, (b) $5 \mathrm{~mm}$, (c) $6 \mathrm{~mm}$, Re: (a) 261,826, (b) 209,235, (c) 174,492 . The legend bar at the bottom shows the velocity estimation for (a)-(c). (d) Variation in the volume fractions of the low velocity regions from 2 to $10 \mathrm{~s}$, with tuyere diameters of $4 \mathrm{~mm}, 5 \mathrm{~mm}, 6 \mathrm{~mm}$, and bath depth of $100 \mathrm{~mm}$.

(a)

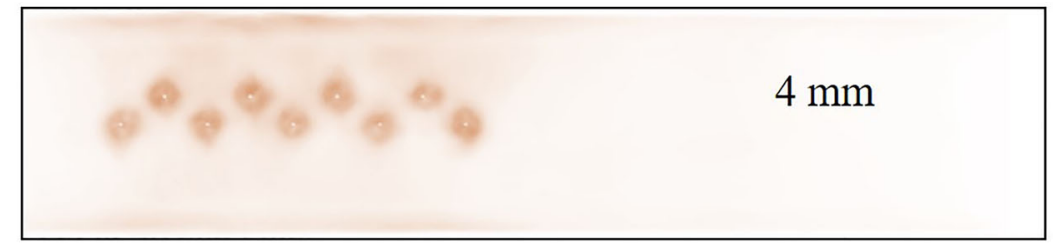

(b)

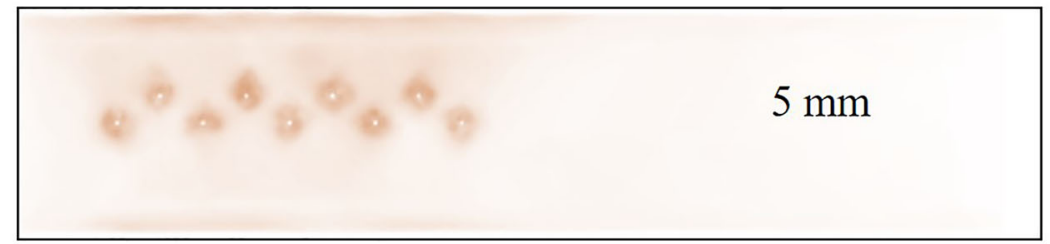

(c)

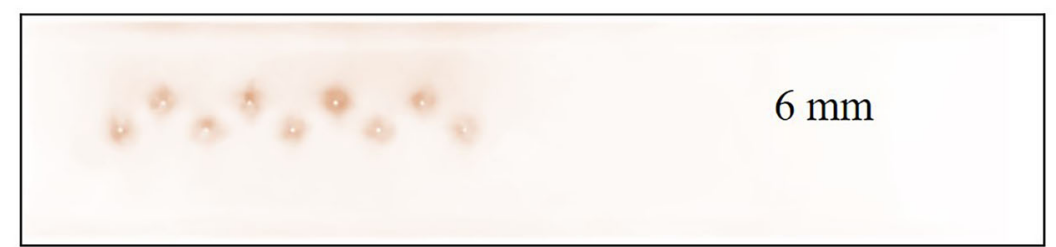

$2.939 \mathrm{e}+00$

$2.755 \mathrm{e}+00$

$2.571 \mathrm{e}+00$

$2.388 \mathrm{e}+00$

$2.204 \mathrm{e}+00$

$2.020 \mathrm{e}+00$

$1.837 \mathrm{e}+00$

$1.653 \mathrm{e}+00$

$1.469 \mathrm{e}+00$

$1.286 \mathrm{e}+00$

$1.102 \mathrm{e}+00$

$9.184 \mathrm{e}-01$

7.347e-01

5.510e-01

3.673e-01

$1.837 \mathrm{e}-01$

[Pa]

Fig. 7. Bottom view of the superposition of the wall shear stress in 5-10 s. The images were taken each $0.25 \mathrm{~s}$, and each image has been set with $95 \%$ transparency. Conditions: bath depth $100 \mathrm{~m}$, tuyere diameter: (a) $4 \mathrm{~mm}$, (b) $5 \mathrm{~mm}$, (c) $6 \mathrm{~mm}$. 
saturation generally decreased, suggesting that the impact on the bottom wall was weakened. This indicates that a shallower bath depth is helpful to alleviate the impact on the lining refractory at the bottom wall. The strongest wall shear stress was found in the case of the tuyere diameter of $4 \mathrm{~mm}$, and was slightly decreased with the increased tuyere diameter of $5 \mathrm{~mm}$. Moreover, a significantly weak wall shear stress also occurred in the case of the tuyere diameter of $6 \mathrm{~mm}$. Such a variation in wall shear stress agrees well with the low velocity region distribution presented in Fig. 6. As described in both sections 4.1 and 4.2 , the wall shear stress performance is in good accordance with the distribution of low-velocity regions. This proves that smaller low-velocity regions and reduced wall shear stress cannot be achieved simultaneously, and only a balanced state may be found.

\section{Overview of the Agitation Performance in All Investigated Conditions}

In general, with a certain total gas volumetric flow rate, smaller tuyere diameters usually operate at a comparatively higher gas injection speed, and are expected to result in smaller low-velocity regions or dead zones in the agitation zone. However, in this research, it was found that increasing the bath depth could be an efficient way to optimize the flow fields using a relatively larger tuyere diameter. This provides extra opportunities for industry in that the tuyere diameter could be chosen in a certain range without concern about the behavior of low-velocity regions or dead zones. Compared to adjusting the tuyere diameter in the reported range of 48-72 $\mathrm{mm}$, corresponding to the 4-6 $\mathrm{mm}$ diameters investigated in this simulation, the change in bath depth was found to be able to exert a stronger influence on the flow field velocity distribution. Fig. 8a shows the volume fractions of the low-velocity regions in all of the conditions described in sections 4.1 and 4.2. As shown in Fig. $8 \mathrm{a}$, the volume fraction of the low-velocity regions is significantly increased by decreasing the bath depth from 145 to $100 \mathrm{~mm}$. Compared with the case of a deep bath depth, the expanded low-velocity regions are attributed to insufficient back flow from

(a)

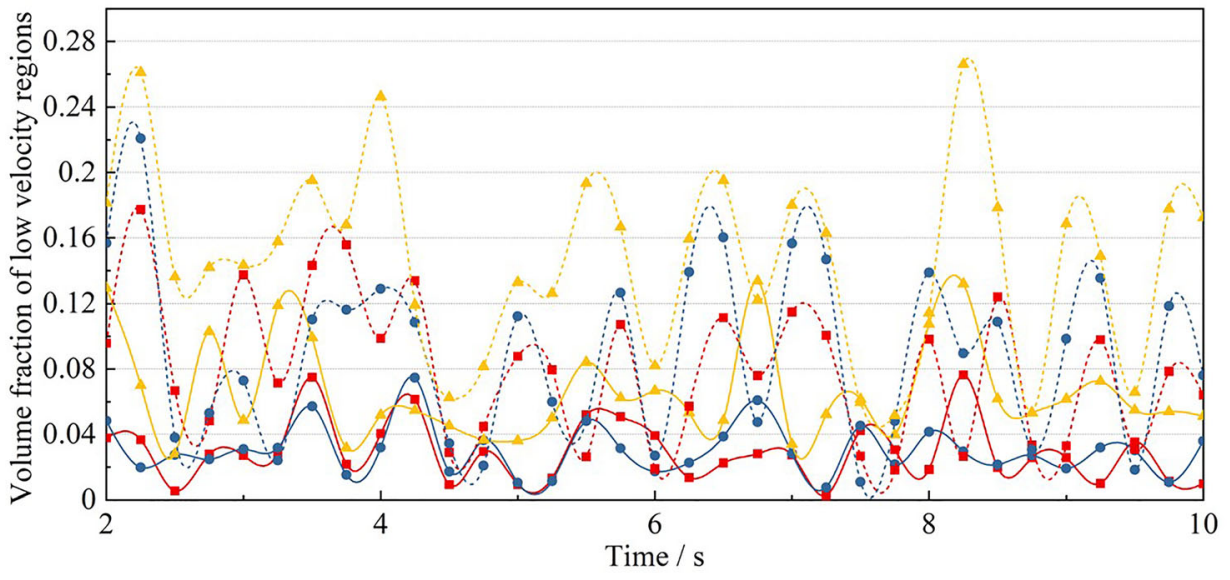

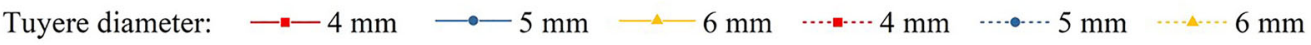
Solid line: bath depth $145 \mathrm{~mm}$, Dashed line: bath depth $100 \mathrm{~mm}$

(b)
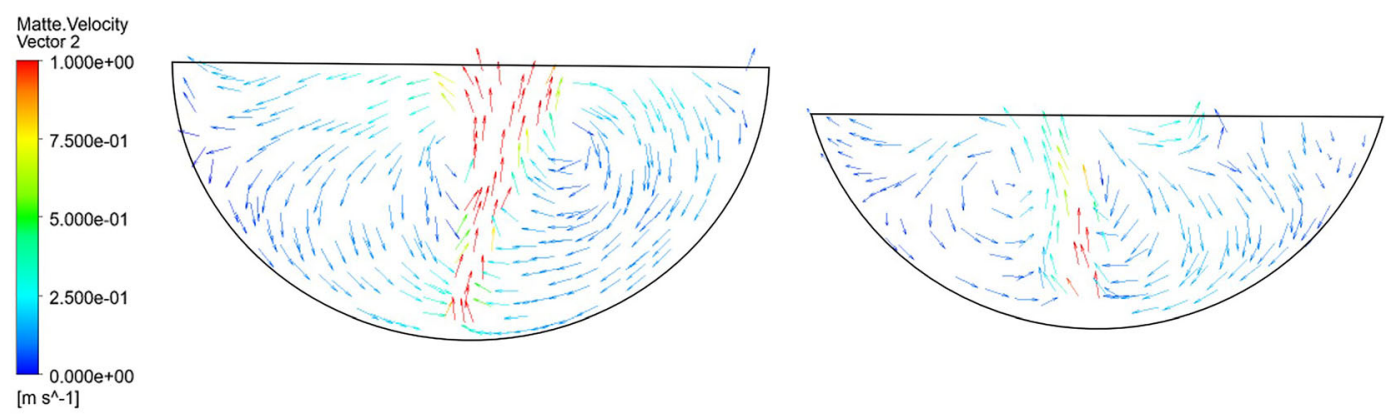

Fig. 8. (a) Volume fractions of the low-velocity regions from 2 to $10 \mathrm{~s}$, with tuyere diameters of $4 \mathrm{~mm}, 5 \mathrm{~mm}, 6 \mathrm{~mm}$, and bath depths of $100 \mathrm{~mm}$ and $145 \mathrm{~mm}$. (b) Matte velocity vectors at the middle bubble plume section at $10 \mathrm{~s}$ for the deep (left) and shallow (right) bath. 
near the liquid level, which is shown using matte velocity vectors in Fig. $8 \mathrm{~b}$. This indicates that increasing the bath depth should be preferentially considered, to promote the agitation performance in the regions at the far side of the bubble plumes.

\section{CONCLUSION}

In this simulation, the low-velocity region distribution and wall shear stress with different tuyere diameters and bath depths were investigated. Based on the comparison and analysis of the simulation results, the following conclusions have been drawn for typical tuyere arrangements with an optimized tuyere angle combination in the investigated conditions:

1. The low-velocity regions are mainly located at either side of the plume zones, irrespective of the tuyere diameter and bath depth.

2. As can be expected, a larger tuyere diameter with a correspondingly lower injection speed does not promote agitation performance in lowvelocity regions. Generally, it leads to expanded low-velocity regions and alleviates the impact on the bottom wall.

3. The wall shear stress strength is correlates well with the distribution of low-velocity regions. Therefore, smaller low-velocity regions and lower wall shear stress cannot be achieved simultaneously.

4. The effect of tuyere diameter on the agitation performance in low-velocity regions is strongly associated with the bath depth. An increased bath depth that provides a longer interaction time for the air and matte phases contributes to their lateral movement, significantly promoting the agitation at the far side of the plumes. This provides more options for the tuyere diameter, because the flow field in the case of impaired gas injection speed for a larger tuyere diameter has been found to be optimized to some extent by a deep bath.

5. In terms of industrial vessel design and operation, it can be concluded that, with a constant gas volumetric flow rate, the tuyere diameter should be selected from a comparatively smaller range. A deep pool depth is recommended as it contributes positively to the agitation performance in low-velocity regions.

\section{FUNDING}

Open Access funding provided by Aalto University.

\section{CONFLICT OF INTEREST}

On behalf of all of the authors, the corresponding author states that there is no conflict of interest.

\section{OPEN ACCESS}

This article is licensed under a Creative Commons Attribution 4.0 International License, which permits use, sharing, adaptation, distribution and reproduction in any medium or format, as long as you give appropriate credit to the original author(s) and the source, provide a link to the Creative Commons licence, and indicate if changes were made. The images or other third party material in this article are included in the article's Creative Commons licence, unless indicated otherwise in a credit line to the material. If material is not included in the article's Creative Commons licence and your intended use is not permitted by statutory regulation or exceeds the permitted use, you will need to obtain permission directly from the copyright holder. To view a copy of this licence, visit $h$ ttp://creativecommons.org/licenses/by/4.0/.

\section{REFERENCES}

1. International Copper Study Group, The World Copper Factbook. (Lisbon, 2020), 35-40.

2. K. Song, and A. Jokilaakso, Miner. Process. Extr. Metall. h ttps://doi.org/10.1080/08827508.2020.1806835 (2020).

3. Z. Liu, and L. Xia, Miner. Process. Extr. M. 128(1-2), 117. (2019).

4. P. Coursol, P.J. Mackey, J.P.T. Kapusta, and N.C. Valencia, JOM, 67(5), 1066 (2015).

5. X. Wan, J. Fellman, A. Jokilaakso, L. Klemettinen, and M. Marjakoski, Metals, 8(11), 887 (2018).

6. X. Wan, P. Taskinen, J. Shi, L. Klemettinen, and A. Jokilaakso: Miner. Eng., 160, 106709 (2021).

7. Y. Yu, Z. Wen, X. Liu, G. Lou, F. Su, R. Dou, X. Hao, and Z. Lu, Nonferr. Met. (Extract. Metal.), 4, 12. (2013) (In Chinese).

8. S. Qu., T. Li, Z. Dong, and H. Luan, Chin. Nonfer. Metal., 1, 10, (2012) (In Chinese).

9. L. Shui, Z. Cui, X. Ma, M.A. Rhamdhani, A. Nguyen, and B. Zhao, Metal. Mater. Trans. B 47, 135 (2016).

10. L. Shui, Z. Cui, X. Ma, M.A. Rhamdhani, A. Nguyen, and B. Zhao, Metal. Mater. Trans. B 46, 1218 (2015).

11. L. Shui, X. Ma, Z. Cui, and B. Zhao, JOM 70(10), 2119 (2018).

12. D. Wang, Y. Liu, Z. Zhang, T. Zhang, and X. Li, Can. Metall. Quart. 56(5), 1 (2017).

13. H. Yan, F. Liu, Z. Zhang, Q. Gao, F. Liu, Z. Cui, and D. Shen, Chin. J. Nonferr. Metal. 22, 2393 (2012).

14. Z. Dong, D. Li, X. Yao, L. Min, B. Li, S. Liang, T. Guo, and Q. Xue, Nonferr. Metal. Eq. 2, 36 (In Chinese) (2019).

15. P. Shao, and L. Jiang, Int. J. Mol. Sci. 20, 5757 (2019).

16. K. Song, and A. Jokilaakso, Metal. Mater. Trans. B 52(3), $1772(2021)$.

17. S. Qu., T. Li, Z. Dong, and H. Luan, Chin. Nonferr. Metal., 1, 10 (2012). In Chinese.

18. X. Jiang, Z. Cui, M. Chen, and B. Zhao, Metal. Mater. Trans. B 50(2), 782 (2019).

19. ANSYS Fluent Theory Guide 19.0, 505-510 (2018).

20. D.K. Chibwe, G. Akdogan, C. Aldrich, and P. Taskinen, Can. Metall. Quart. 52(2), 176 (2013).

21. D.K. Chibwe, G. Akdogan, P. Taskinen, and J.J. Eksteen, J. S. Afr. I. Min. Metall. 115(5), 363 (2015).

22. H. Zhang, C. Zhou, W. Bing, and Y. Chen, J. S. Afr. Inst. Min. Metall. 115(5), 457 (2015).

23. W. Liu, H. Tang, S. Yang, M. Wang, J. Li, Q. Liu, and J. Liu, Metal. Mater. Trans. B 49(5), 2681 (2018).

24. ANSYS Fluent Meshing User's Guide 17.0, 313 (2016).

Publisher's Note Springer Nature remains neutral with regard to jurisdictional claims in published maps and institutional affiliations. 